\title{
Partnering Public and School Librarians for School Readiness Programming
}

A side from storytimes in the library's space, it can be tricky to bring the community to the library to gain early childhood literacy. As a public librarian, it is imperative to find the resources out in the community that helps every type of family with providing school readiness services to their child. Families have different needs that cannot be encompassed in a weekly storytime program. School librarians are finding that students are entering school with a lack of preparation for being in school. Networking with a school librarian, who is more familiar with school standards and curriculum to prepare children for Kindergarten, can prove to be a fantastic collaboration in creating a program to combat this dilemma.

School Readiness Fairs are similar to career fairs, except the focus is on bringing early childhood organizations from the community to speak on the resources and services that they have to offer their children. Local daycares, schools, partnerships for children, and the library in general have a lot of services that the community's caregivers are not aware of. According to Baker (2015) "A large one-time event allows you to connect adults with other early childhood services in your community, and it provides the opportunity to promote your lengthier programs to the adults who attend" (p. 103). Having a school readiness fair can help bridge the gap of knowledge and bring equity to allow every type of family to be at the same starting place. From financial issues, mental or physical disabilities, to lack of knowledge in the community, caregivers have different needs that organizations can meet to create a more equitable start of school. There are many reasons these children do not attend formal preschool, including lack of transportation, socio-economic status, or lack of opportunities nearby, but it is important to remember that the library can assist in this endeavor by bringing the resources to one location, the school readiness fair. The focus of this school readiness fair is for caregivers that have children who are about to start Kindergarten within a year. By bringing in families that have 4-year-olds, it helps caregivers use the techniques and resources before their child enters Kindergarten.

As the public librarian, doing early childhood programs is a normal aspect of library work. Storytimes are a quintessential part of the library that can oftentimes be overlooked. Public librarians help prepare children for basic school readiness but may not know what children are required to know when entering Kindergarten, curriculum standards, or the services offered by schools nearby. Having an ally who is in the school system when doing school readiness programs helps flesh out the programs to be filled with substantial knowledge instead of just fluff. An ally who is familiar with library work and knows the goals of the library is ideal, making that perfect ally the school librarian.

\section{Networking with School Librarians}

Making connections in other disciplines of librarianship, school to public and vice-versa, can seem intimidating, but after making the relationship, it will prove to be most beneficial. Oftentimes librarians are scared to network outside of their discipline due to a lack of understanding on what the other person does on their end. Creating these opportunities to connect creates a better understanding and appreciation of what each discipline is doing for the community's children.

Networking locally can be a struggle with various schedules. School librarians have tight schedules due to the constraints of classes, circulation time slots, and collaborations with teachers. Finding time to collaborate during the school year is tough to do, but making those connections early allows for better time management in both schedules. Networking across the state or nation can be a bit trickier but can prove to be quite beneficial for idea building. Attending library conferences with the intent on networking is a great way to meet those who could help be great assets in partnering with ideas. Through conferences, social media groups, or emailing, networking nationally is an easier way to connect without the issue of scheduling in person.

Once a partnership is created between the school librarian and the public librarian it is best to establish the goals of the program. The overall goal is to provide school readiness information and resources to caregivers and their children. To determine how to divvy the work up is to determine what the strengths are of the public and school librarians. Public librarians experience working with children and their caregivers together, while the school librarians usually work with solely the children. This can help allow for the public librarian to know what the community's needs are from the 
librarians, and the school librarian can help with designing the content for what the children need to know. Splitting up the tasks like this requires trust, but when trust is there, it will make the planning easier to handle. Next, determine what connections and networking have already been established outside of the library through community members. These are the speakers or vendors at the community fair who will be talking to the caregivers. Having local community members helps boost their programs as well as brings more people into the library. The partnership helps out everyone involved with outreach and marketing. Bringing more community members into the fair, helps bring out more information to the caregivers.

\section{Networking Outside of the Library}

After finding a school librarian to partner in the program, it is best to find other leaders in early childhood literacy within the community. Many communities have a plethora of resources to offer families, but oftentimes the options begin to muddle together. That is how the school readiness fair can help provide all of the options in the same place for the caregivers to learn about. The public and school librarian should research and determine which organizations should be included into the fair to best offer their resources. Cold calls to organizations may seem intimidating, but oftentimes organizations who share the same goal will find a way to participate. Understand that various schedules could conflict with the program. See if there are other members who are willing to represent the organization on their behalf. It is important to have various organizations represented to provide the most diverse information to caregivers of all backgrounds and needs. Some caregivers may want to place their child in private schools, so a private school representative is helpful to have. Caregivers may need information on reduced lunch and how to find free school supplies, so having those options available for every type of family brings out more people.

School librarians work with many early childhood leaders within the school, such as Kindergarten teachers, principals, school counselors, and social workers. The school librarian can be a great mutual partner in helping obtain the teacher, since they have the most experience working with them. Kindergarten teachers are the ones who know what children need to know before entering school, so they are truly great mentors to the program and what it needs to entail. Caregivers will value meeting kindergarten teachers to help visualize their child's preparation for entering school. Administrative representatives and social workers provide ease of access for caregivers to ask for sources of financial assistance with lunch or school supplies. Having a school partner in the program will allow the caregivers attending the programs to be more acclimated to the local elementary school, allowing them to feel at ease to build up rapport with the administration and staff members.

The partnership for children is a great organization to make connections with due to their exclusive expertise in the birth to kindergarten age range. The partnership has all of the appropriate resources to give to caregivers of all socio-economic backgrounds. Many offer free Pre-K to families that qualify. Children can receive a head start on preparing for school readiness through this program that many families do not know they qualify for. Having these partnerships with these various community leaders helps provide the information and resources to the caregivers empowering them and their children.
After building up the relationships, creating a partnership in programming will be easier to do versus rightly asking someone to do a collaboration in programming. Knowing that the other librarian has the same goals and abilities is helpful in creating a consistent program. At the end of the day, the goal is to bring in diverse families to prepare for early literacy and school readiness. Having this goal on the forefront makes it easier to network with others.

\section{Developing the Storytime Program}

When developing the program for families, it is best to decide the layout of the fair. The vendors will need space in order to set up their booths to meet with caregivers. If space is available, there could be scheduled storytimes to do with caregivers and their children to help show caregivers examples of what they could be doing at home. While it is helpful for the librarian to do these activities with the children in the library, the caregiver is the child's first teacher. Knowing this relationship and empowering caregivers with this role is key in creating a successful readiness program. Teaching caregivers tips and techniques to do at home will help build a routine. Having a song to start off with, a book to read, and a song to finish off with, can allow for a quicker sample storytime program for caregivers to return back to the booth area. Reiterate to caregivers that storytime happens frequently, often encompassing many different subjects and areas for growth. Having this sample storytime will help caregivers see library programs in a newer light.

Structuring the storytime using practices from Every Child Ready to Read can help establish to caregivers the standard of what storytimes should look like. Many libraries across the nation use Every Child Ready to Read 
practices to structure their storytimes due to its proven level of success. These can be done by the five practices of early literacy: play, read, sing, talk, and write. According to their website, Every Child Ready to Read (n.d.) is a program created by the Public Library Association and the Association of Library Services to Children in 2004, to help enhance library storytime and school readiness programs. Incorporating these within the programming will help prepare children for early literacy and school. Due to Every Child Ready to Read being mainstream across children's libraries across the country it should be easier to incorporate it into the school readiness program to educate its effectiveness to caregivers.

\section{Developing the School Readiness Fair}

School Readiness Fairs bring the community together by having the leaders of early childhood literacy together providing caregivers the best resources that the community has to offer. Having representatives present helps put a face to a name, allowing connections to be made. Representatives are performing outreach to push out the resources that they have, while caregivers are given everything that they need and more.

After arranging the storytime space for caregivers to sample activities to do with their children at home and at the library, next would be the boots from the organizations. Having space in between each of the booths will allow for caregivers to move freely through each one and have room to have conversations about their child's needs. Encourage the organizations to bring their outreach materials (brochures, tablecloths, posters, etc.) to allow caregivers to know who and what each booth is before they talk to the representative. Having different organizations grouped together based on services provided will also help show the options available to the caregivers. Having public and private schools' booths nearby each other will help caregivers remember those interactions easier. Lastly, it is important to remember to trust the organization's booth representatives to advocate their programs to the caregivers. Not everything in the program can and should be planned. Caregivers will gain a lot from the program, so much that it may be overwhelming to them at first, but in the end, they will be grateful for the knowledge.

\section{Booth Ideas from the Library}

Other great booth ideas are ones that support the library's resources and services. Many tables could be set up to promote what the library has to offer. If possible, the best way to advocate for the library's early education programming could be done on a microphone to introduce and begin the school readiness fair. Introducing the public and school librarians as the collaborating hosts for the school readiness fair, explaining what organizations are there, and advocating for the school readiness programs that the library has to offer, is a great way to kick off the event. While all of the organizations are there to showcase their resources, it is the library's program in their space. As the public and school librarian hosting the program, there may be other things that need tending to during the program that could take away from recommending library resources. So, recommending and advocating for library services during the introduction can help alleviate the public and school librarians to handle other things.

The library's story times are one of the biggest early literacy programs that should be mentioned during the introduction. Explaining and advocating for storytimes helps caregivers see the merit of storytimes, instead of it being "play time" for their children. According to Baker (2015), "One of the main reasons for this lack of universal awareness is the public library's oversight to intentionally advocate for their own programs as school readiness resources" (p. 7). Explaining to caregivers that storytimes tend to have a structure following Every Child Ready to Read helps promote the merit behind these programs. Reading the book and singing songs during storytime accomplishes the reading and singing practices. If the activity at the end includes use of a writing utensil (crayons, markers, paint brush) it can be writing. At the beginning of the program introducing one another and talking during the activity can fulfill the talking practice. Finally, if the activity is instead using sensory toys or games to socialize, it can fulfill the play practice. These all contribute to building early literacy that caregivers should know about. Advocating this during the introduction to everyone helps them understand the work and effort put together to bring about early literacy.

Outside of the introduction, table booths could be there to advocate for other services. Programs for children are important, but while the caregivers are there mention some other services offered that could benefit the whole family. Older children's programs, teen programs, adult programs, audiobooks, e-book applications, and the computer lab are all services that caregivers forget about. Reminding them of the services available will help them see the other opportunities available at the library to help them grow. Having a booth on helping caregivers set up their e-book application on their phone can be a great start to quickly bring new readers to use it, who may not have done so before. Another booth advocating for the programs that the library has to offer, outside of early literacy, 
can show that caregivers other children or family members could gain from coming to the library's events. Even though it is a school readiness fair for early childhood, that does not mean that the caregivers cannot receive valuable information for their other older children.

\section{More than "Just for Kids"}

Oftentimes the problems in school readiness programs lie in the misconception that the storytimes are just for the kids' benefit. Storytimes and school readiness programs can and should be just as much for the caregivers as it is for the children. As stated earlier, the caregiver is the first teacher that the child has in their life. According to Baker (2015) "Children begin learning from their parents as soon as they are born, even if parents are not aware that it is happening. School readiness programs at the library should model practices in a way that honors the parents as their child's best teacher while also helping the parent to build their literacy practices" (p. 19). Empowering the caregiver is the main goal of the school readiness program. Providing these resources and tips are not benefiting the child so much, but the caregiver. Doing the activities and reading the stories are engaging and fun for the child, but these are things that caregivers should learn how to do at home to keep educating their child outside of the library. By empowering the caregiver, it helps give them the confidence they need to further prepare their child for school. Modeling the behaviors and techniques learned in the library's program can go a lot further if done routinely in the child's life.

The goal of the event is to help promote to caregivers the resources they need to help promote early literacy at home. According to Trelease (2019) "The one prekindergarten skill that matters above all others, because it is the prime predictor of school success or failure, is the child's vocabulary upon entering school. Yes, the child goes to school to learn new words, but the words he already knows determine how much of what the teacher says will be understood" (p. 10). Bringing their child to storytimes and other programming helps, but caregivers need to be empowered to know that they can do storytime at home. Storytimes help add in new vocabulary words that build up over time, helping the child understand more and more of the world around them. Caregivers are the ones who promote this within the home. Caregivers can help children practice writing. Caregivers can use the information learned at the event to allow their child a head start into their education. At the end of the program, librarians, school or public, are there to help caregivers take charge of their child's education.

\section{Conclusion}

Collaboration with the school librarian to create school readiness programs can be a fulfilling relationship that could turn into an annual program. Other ideas or collaborations can come from the partnership, making it important to make connections with the schools nearby. Constant advocating for public and school library programs can bring about a community awareness for how important the library is. According to Baker (2015) "Do not keep your successes to yourself when your program might make an impact on other communities" (p. 98). Baker is saying that libraries should spread the word to other librarians in other communities to lead the way for school readiness programs and what works. Bringing awareness to school readiness programs brings more families to the next storytime or event allowing for more patron usage all around. Overall, networking and collaborating outside of the public library can provide a lot of opportunities for learning about the community around the library, so that way as a librarian more knowledge can be returned to the patrons that walk into the library every day.

\section{References}

Every Child Ready to Read (n.d.). About. Every Child Ready to Read. Retrieved June 13, 2021 from http://everychildreadytoread.org/about/

Baker, L. (2015). Counting down to kindergarten: A complete guide to creating a school readiness program for your community. ALA Editions, Chicago: IL.

Trelease, J. (2019). Jim Trelease's readaloud handbook. Eighth Edition. (C. Giorgis, Ed.). Penguin Books, London: United Kingdom.

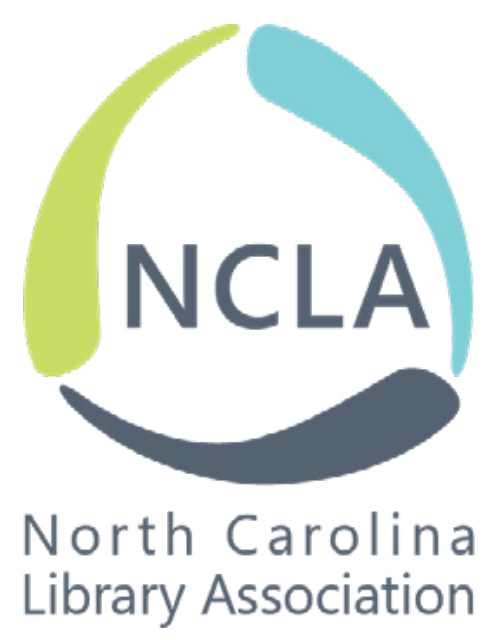

